\title{
Modeling of Dynamics and Thermal History of Fe40Al Intermetallic Powder Particles Under Gas Detonation Spraying Using Propane-Air Mixture
}

\author{
Bartosz Fikus $^{1}$ - Cezary Senderowski ${ }^{2}$ Andrzej J. Panas ${ }^{3}$
}

Submitted: 24 June 2018/in revised form: 8 January 2019/Published online: 6 February 2019

(C) The Author(s) 2019

\begin{abstract}
The dynamic properties and thermal history of Fe40Al at.\% intermetallic particles have been estimated. The parameters of the gas detonation process for the investigated mixture have been calculated using thermochemical code, and the motion parameters as well as thermal history of the analyzed powder particles have been assessed using computational fluid dynamics software and self-developed algorithms. The appropriate models allowed for determination of the melted volume (mass) fraction of a certain analyzed single particle, which is dependent on a particle diameter ranging from 10 to $160 \mu \mathrm{m}$. The results show that only particles with a diameter lower than $80 \mu \mathrm{m}$ melt under the investigated conditions. Moreover, the estimated radial distribution of the temperature inside the particle is almost homogenous due to relatively high $\mathrm{FeAl}$ thermal conductivity and relatively low thermal conductance of the surface heat transfer. The calculated final
\end{abstract}

This article is an invited paper selected from presentations at the 2018 International Thermal Spray Conference, held May 7-10, 2018, in Orlando, Florida, USA, and has been expanded from the original presentation.

Bartosz Fikus

bartosz.fikus@wat.edu.pl

Cezary Senderowski

cezary.senderowski@uwm.edu.pl

Andrzej J. Panas

andrzej.panas@itwl.pl

1 Faculty of Mechatronics and Aerospace, Military University of Technology, Warsaw, Poland

2 Department of Materials Technology and Machinery, University of Warmia and Mazury, Olsztyn, Poland

3 Department of Aircraft and Helicopters, Air Force Institute of Technology, Warsaw, Poland velocity of particles has been referred to some experimental and literature data from previous studies by other researchers, and the results were found to be in agreement.

Keywords CFD - FeAl intermetallic powder - gas detonation spraying - numerical hybrid modeling - particle dynamics $\cdot$ particle thermal history $\cdot$ thermochemical code

\section{List of Symbols}

$a_{1}, a_{2}, a_{3}$ Constants in Eq $13 \mathrm{c}$

A Constant in the Arrhenius relation (8a)

$\bar{A} \quad$ Linearized Jacobian matrix of system of equations

BL Barrel length

$c\left(T_{\mathrm{p}}\right) \quad$ Specific heat of particle material

$C_{1 \lambda}, C_{2 \lambda} \quad$ Constants in Sutherland relation describing thermal conductivity

$C_{1 \mu}, C_{2 \mu} \quad$ Constants in Sutherland relation describing dynamic viscosity

$C_{\mathrm{D}} \quad$ Drag coefficient of the spherical particle

$C_{j} \quad$ Molar concentration of $j$ th reactant

$C_{m i} \quad$ Constants defining specific heat of gaseous component for certain temperature subintervals

$c_{p}(T) \quad$ Specific heat of gas at constant pressure

$c_{p i} \quad$ Specific heat of $i$ th gaseous component at constant pressure

$d_{\mathrm{p}} \quad$ Diameter of the spherical particle

$E \quad$ Total energy per unit mass

$E_{\text {a }} \quad$ Energy of activation

$F \quad$ Flux vector

$F_{\mathrm{d}} \quad$ Drag function

$F_{\mathrm{L}} \quad$ Flux vector for left numerical cell

$F_{\mathrm{R}} \quad$ Flux vector for right numerical cell

$k \quad$ Arrhenius term 


$\begin{array}{llll}\bar{K}^{(i)} & \begin{array}{l}\text { Right eigenvector for the linearized Jacobian } \\ \text { matrix }\end{array} & \rho_{\mathrm{p}} & \begin{array}{l}\text { Particle m } \\ \text { Stefan-B }\end{array} \\ M_{w} & \text { Molar mass of gas } & & \\ M_{w i} & \text { Molar mass of } i \text { th component of gas } & \text { Selected Subscripts } \\ N & \text { Number of gaseous components } & \text { mel Melted state } \\ N u_{\mathrm{p}} & \text { Nusselt number for particle } & \text { sol Solid state } \\ p & \text { Pressure } & \end{array}$

\section{Introduction}

Theoretical estimation of motion dynamics and the temperature history of powder particles during gas detonation spraying (GDS) is a crucial issue in adjustment of the GDS process parameters to powder particle size distribution and particle material physical properties in view of the required coating properties. As shown in (Ref 1,2), the appropriate analyses involve problems characterized by coupling of mechanical and thermodynamic phenomena. This state of matter seriously limits the availability of analytical solutions and hinders developments of general models describing the investigated problem. Variety of parameters of spraying system and diversity of applicable powder materials, which differ in values of thermophysical and mechanical parameters describing the behavior of possible media during spraying process, result in the need to analyze every single case individually. Some of the first reports in this domain were provided in papers by Kadyrov (Ref 3,4) and Ramadan and Butler (Ref 5,6). In publication (Ref 3), which was based on simplified analytical model of detonation, E. Kadyrov and V. Kadyrov investigated the process of propulsion of powder particles. The authors estimated the muzzle velocity of powder particles, using a simple one-dimensional detonation model for the explosive gas mixture. Furthermore, this approach required the application of numerical integration of the differential equation of motion for a particle. The analytical model was developed in order to describe the detonation process in the barrel. Consequently, making use of numerical schemes, the thermal interaction between powder and gaseous medium has been investigated (Ref 4). In both cases, the authors (Ref 3,4) used a one-dimensional model and their considerations were limited to motion of the powder-gas mixture only in the barrel. In order to reduce the effects of these drawbacks, the authors of (Ref 5, 6) proposed a twodimensional numerical model which allowed for considerations of additional effects, for example, particle interaction with reflected waves and the motion and thermal interaction of powder in the external conditions.

In the analyzed case of pulsed detonation, the flow is unsteady. As shown in Ref 5, during the spraying process, the moving powder particle faces with significant changes of thermodynamic and mechanical parameters of 
surrounding gas (Ref 5). The shock wave spreading from the barrel outlet reflects from the flat rigid substrate surface. Because the wave is spherical outside the barrel, its intensity decreases proportionally to the square of the distance covered. The reflected shock wave from the substrate dies out extremely fast. Thus, micron-sized particles used in the GDS process do not encounter these shock wave transients (Ref 5, 6). As proven by Sova et al. (Ref 7), the GDS technique is characterized by higher complexity level in comparison with another spraying methods. This results in much more difficult theoretical description of phenomena during powder propulsion and structure formation. This problem was additionally described in experimental and theoretical papers (Ref 8-10), where authors underlined the complexity of the technique and necessity of individual approach to the GDS spraying problem. In accordance with cited sources, for so fast and highly non-equilibrium process, it is extremely difficult to identify and describe all the phenomena shaping the spraying process and defining its results.

Regarding the need for an individual approach for every single GDS problem, a methodology of a hybrid numerical analysis was elaborated and applied for a certain GDS case of intermetallic Fe40Al at.\% particles. The applied methodology is based on approaches proposed by Kadyrov and Ramadan (Ref 3-6). Similar to those analyses, a oneway coupling between solid and gaseous phases was applied. In contrast to previous ones, the present analysis also accounts for heat conduction inside Fe40Al at.\% particles, which additionally extend the applicability of the model. For a problem solution, a thermochemical code and commercial CFD software were applied. Eventually, the methodology was applied for determination of the terminal state of intermetallic Fe 40Al at.\% powder particles under certain experimental conditions, in which not only the particle velocity and temperature are sought, but also the different size of particles, which remain in solid state during coating formation once the substrate material is impacted.

These results are necessary as the initial conditions for simulations of terminal ballistics processes occurring during interaction of heated particles with the sprayed surface.

The $\mathrm{Fe}-\mathrm{Al}$ phase equilibrium system shows that the high-temperature $\mathrm{FeAl}$ phase solution (the composition of which is very close to stoichiometric) is resistant to the temperature of $1310^{\circ} \mathrm{C}$ (Ref 1). This fact is highly important because in view of lack of the feedstock material melting in the GDS process, the GDS produced coating can preserve the phase structure and the chemical composition of the FeAl powder used at a great extent. Thus, the fundamental problem when designing the GDS process is to select and apply spraying parameters ensuring that the intermetallic particles of powder feedstock will retain solid but with a substantially decreased Young modulus value.

\section{Physical and Mathematical Model of the Problem}

\section{Physical Model of the Problem}

Similar to Ref 5 and 6 , in the present study, the whole model consists of four main modeled elements (Fig. 1): a barrel filled with explosive gas mixture, substrate (sprayed surface), the surrounding air and powder particles injected into the barrel at the powder injection point (PIP). Taking into account the geometry of the whole system, it seems to be reasonable to conduct numerical experiments using a $2 \mathrm{D}$ axisymmetric model.

In the presented investigations, the reactant propaneoxygen-air mixture was considered. The volume fractions of reactants were as follows: propane: 0.202 and oxygen: 0.685 . The barrel length was equal to $590 \mathrm{~mm}$ and was characterized by interior diameter of $23 \mathrm{~mm}$. The PIP was located $275 \mathrm{~mm}$ from the barrel bottom.

The whole analysis was restricted to one single cycle of gas detonation and particle propulsion. At the initial time of $t=0$, the detonation process is initialized on the bottom of the barrel (at the axial coordinate $x=0$ ). The detonation wave propagates through the barrel, and the products of detonation drive the powder particles. The crucial stage of propulsion takes place in the interval of gas outflow from the barrel, so it is necessary to investigate this process. At present analysis, it was assumed that the ignition occurs within the high-temperature region and the chemical reaction spreads outside from there. The total particle sizes range from $d_{\min }=10 \mu \mathrm{m}$ to $d_{\max }=160 \mu \mathrm{m}$. The particle calculations were started at the same time and location for different particle sizes $(10,20,4060,80,100,120,160$

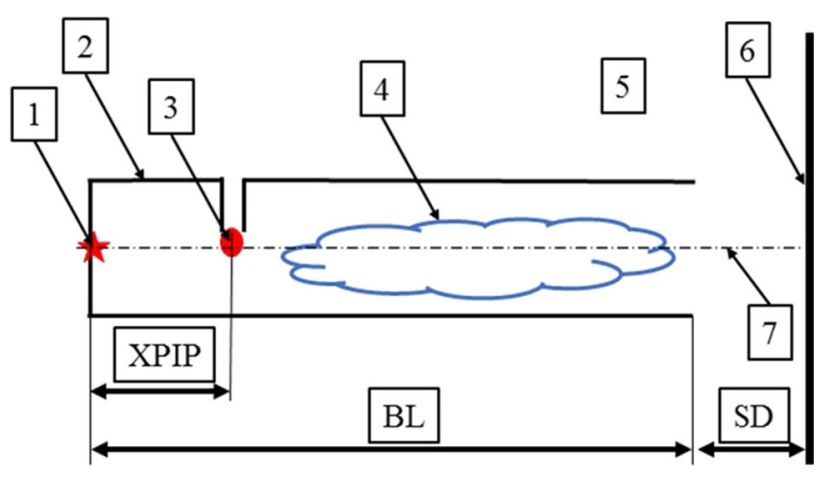

Fig. 1 Scheme of gas detonation spraying system (1-detonation initiation point, 2-barrel, 3-powder particles at powder injection point, 4-explosive gas mixture, 5-air surrounding spraying system, 6-substrate 7-axis of the symmetry of the barrel, BL-barrel length, SD-spraying distance, XPIP-distance between powder injection point and the barrel bottom) 
microns), and the simulation was terminated when the largest particle reached the coated surface.

\section{Mathematical Formulation of the Problem}

Taking into account the assumed axial symmetry of the considered problem, the gas dynamics are described by the equations of conservation of mass, momentum and energy, which can be written in the following form (Ref 11):mass continuity equation:

$\frac{\partial \rho}{\partial t}+\frac{\partial\left(\rho v_{x}\right)}{\partial x}+\frac{\partial\left(\rho v_{\mathrm{r}}\right)}{\partial r}+\frac{\rho v_{\mathrm{r}}}{r}=0$

equations of species transport:

$\frac{\partial \rho Y_{i}}{\partial t}+\frac{\partial\left(Y_{i} \rho v_{x}\right)}{\partial x}+\frac{\partial\left(Y_{i} \rho v_{\mathrm{r}}\right)}{\partial r}+\frac{Y_{i} \rho v_{\mathrm{r}}}{r}=R_{i}$

momentum equations:

$$
\begin{aligned}
& \frac{\partial\left(\rho v_{x}\right)}{\partial t}+\frac{1}{r} \frac{\partial\left(r \rho v_{x} v_{x}\right)}{\partial x}+\frac{1}{r} \frac{\partial\left(r \rho v_{x} v_{\mathrm{r}}\right)}{\partial r} \\
& =-\frac{\partial p}{\partial x}+\frac{1}{r} \frac{\partial}{\partial x}\left[r \mu\left(2 \frac{\partial v_{x}}{\partial x}-\frac{2}{3}(\nabla \cdot \vec{v})\right)\right] \\
& \quad+\frac{1}{r} \frac{\partial}{\partial r}\left[r \mu\left(\frac{\partial v_{x}}{\partial r}+\frac{\partial v_{\mathrm{r}}}{\partial x}\right)\right] \\
& \frac{\partial\left(\rho v_{\mathrm{r}}\right)}{\partial t}+\frac{1}{r} \frac{\partial\left(r \rho v_{x} v_{\mathrm{r}}\right)}{\partial x}+\frac{1}{r} \frac{\partial\left(r \rho v_{\mathrm{r}} v_{\mathrm{r}}\right)}{\partial r} \\
& =-\frac{\partial p}{\partial r}+\frac{1}{r} \frac{\partial}{\partial x}\left[r \mu\left(2 \frac{\partial v_{\mathrm{r}}}{\partial r}-\frac{2}{3}(\nabla \cdot \vec{v})\right)\right] \\
& \quad+\frac{1}{r} \frac{\partial}{\partial r}\left[r \mu\left(\frac{\partial v_{x}}{\partial r}+\frac{\partial v_{\mathrm{r}}}{\partial x}\right)\right]-2 \mu \frac{v_{\mathrm{r}}}{r^{2}}+\frac{2}{3} \frac{\mu}{r}(\nabla \cdot \vec{v})
\end{aligned}
$$

energy equation:

$$
\begin{aligned}
& \frac{\partial(\rho E)}{\partial t}+\nabla \cdot(\vec{v}(\rho E+p))=R_{h} \\
& +2 \mu\left[\left(\frac{\partial v_{\mathrm{r}}}{\partial r}\right)^{2}+\left(\frac{v_{\mathrm{r}}}{r}\right)^{2}+\left(\frac{\partial v_{x}}{\partial x}\right)^{2}\right] \\
& \quad+\mu\left(\frac{\partial v_{x}}{\partial r}+\frac{\partial v_{\mathrm{r}}}{\partial x}\right)^{2}-\frac{2}{3} \mu\left(\frac{1}{r} \frac{\partial\left(r v_{\mathrm{r}}\right)}{\partial r}+\frac{\partial v_{x}}{\partial x}\right)^{2}
\end{aligned}
$$

In the above equations, the following denotations were used: $\rho$-gas density, $t$-time, $v_{x}$-axial component of gas velocity, $v_{r}$-radial component of gas velocity, $x$-axial coordinate, $r$-radial coordinate, $Y_{i}$-concentration of the species $i, R_{i}$-source term of species $i, p$-pressure, $\mu$ dynamic viscosity, $E$ - total energy per unit mass, and $R_{h}$ the source, which represents the energy source due to the chemical reaction.

With regard to the low values of pressure of detonation products in the case of gaseous explosive mixtures (several megapascals), the equation of state for perfect gas has been selected (Ref 12):

$p=\rho \frac{R}{M_{w}} T$

where $R$ denotes the universal gas constant, $T$ is the temperature, and $M_{w}$ is the molar mass of gas.

The "reaction term" in Eq 2 represents the kinetics of chemical reactions in the detonation wave. In the presented paper, this term is based on the Arrhenius law (Ref 11, 13). The source of chemical species $i$ generated by chemical reaction $R_{i}$ is calculated based on molar rates of destruction/creation of species $i$ :

$R_{i}=M_{w i} \bar{R}_{i}$

The molar rate $\bar{R}_{i}$ is estimated by the following relation:

$\bar{R}_{i}=\left(v_{i}^{\prime \prime}-v_{i}^{\prime}\right)\left(k \prod_{j=1}^{N} C_{j}^{\left(\eta_{j}^{\prime}\right)}\right)$

where

$k=A T^{\beta} e^{-E_{\mathrm{a}} / R T}$

$C_{j}$ denotes the molar concentration of each reactant, $\eta_{j}^{\prime}$ is the rate exponent for each reactant, $\beta$ is the temperature exponent in the Arrhenius law, and $E_{\mathrm{a}}$ is the energy of activation.

The coefficients in $\mathrm{Eq} 8$ and $8 \mathrm{a}$ have been selected to

\begin{tabular}{|c|c|c|c|}
\hline \multicolumn{2}{|c|}{ Reactants } & \multicolumn{2}{|c|}{ Products } \\
\hline Symbol & Mass fraction, $\%$ & Symbol & Mass fraction, $\%$ \\
\hline $\mathrm{C}_{3} \mathrm{H}_{8}$ & 26.2 & $\mathrm{H}_{2} \mathrm{O}$ & 29.8767 \\
\hline $\mathrm{O}_{2}$ & 66.5 & $\mathrm{CO}$ & 44.0411 \\
\hline $\mathrm{N}_{2}$ & 7.2 & $\mathrm{H}_{2}$ & 1.4390 \\
\hline $\mathrm{Ar}$ & 0.1 & $\mathrm{~N}_{2}$ & 5.6699 \\
\hline Ch-J para & & $\mathrm{CO}_{2}$ & 9.3105 \\
\hline$a_{\mathrm{ChJ}}, \mathrm{m} / \mathrm{s}$ & 1425 & $\mathrm{O}_{2}$ & 6.1479 \\
\hline$D, \mathrm{~m} / \mathrm{s}$ & 2614 & NO & 3.5111 \\
\hline$u_{\mathrm{ChJ}}, \mathrm{m} / \mathrm{s}$ & 1188 & $\mathrm{NO}_{2}$ & 0.0037 \\
\hline$p_{\mathrm{ChJ}}, \mathrm{MPa}$ & 4.444 & $\mathrm{~N}_{2} \mathrm{O}$ & 0.0000 \\
\hline$T_{\mathrm{ChJ}}, \mathrm{K}$ & 4461 & $\mathrm{NH}_{3}$ & 0.0002 \\
\hline
\end{tabular}
adjust the gas parameters at the Chapman-Jouguet ( $\mathrm{Ch}-\mathrm{J}$ ) surface to values obtained from the thermochemical code TIGER (Ref 1). Taking into account that the parameters of the detonation wave determine the dynamics of the whole process, in Table 1, the values of crucial parameters of the

Table 1 Summary of crucial parameters describing the front of the detonation wave in propane-oxygen-air mixture obtained with TIGER thermochemical code (Ref 1) 
wave and the compositions of reactants and products are summarized.

In the analyzed case, the gas properties are strongly dependent on temperature. The dependence of temperature on the dynamic viscosity of applied media was included in the Sutherland form (Ref 11):

$\mu_{i}=\frac{C_{1 \mu i} T^{1.5}}{T+C_{2 \mu i}}$

where the constants $C_{1 \mu}$ and $C_{2 \mu}$ were estimated using thermophysical tables included in (Ref 1, 14). The value of dynamic viscosity for a mixture was estimated using the molar fractions $z_{i}$ and values of viscosity $\mu_{i}$ for the respective species:

$\mu_{\text {mix }}=\sum_{i=1}^{N} z_{i} \mu_{i}$

For the investigated detonation products, these constants were $C_{1 \mu}$ DP $=1.7 \times 10^{-6}$ and $C_{2 \mu}$ DP $=900$. Using a similar approach, the Sutherland coefficients for approximation of the thermal conductivity of detonation products were

$C_{1 \lambda \mathrm{DP}}=4 \times 10^{-3}$ and $C_{2 \lambda \mathrm{DP}}=200$.

The specific heat of a species was assumed to be dependent on temperature in the piecewise polynomial form:

$c_{p i}=C_{0 i}+C_{1 i} T+C_{2 i} T^{2}+C_{3 i} T^{3}+C_{4 i} T^{4}$

where $C_{m i}(m=0, \ldots, 4)$ are constants for certain temperature subintervals.

All the boundaries of the computational domain (except the axis of symmetry) were treated as the walls, which imposes the nonslip and reflecting boundary conditions for the problem of gas dynamics. This approach results in values of components of gas velocity on the boundaries of computational domain, which can be presented in the following general form:

$v_{\text {perp }}\left(x_{\text {wall }}, r_{\text {wall }}, t\right)=0, \quad v_{\text {par }}\left(x_{\text {wall }}, r_{\text {wall }}, t\right)=0$,

where $v_{\text {perp }}, v_{\text {par }}$ denote perpendicular and parallel (to the wall surface) components of the gas velocity, $x_{\text {wall }}$ and $r_{\text {wall }}$ are the wall coordinates in the cylindrical coordinate system.

The initial temperature of the investigated media was assumed to be $300 \mathrm{~K}$ except a small region neighboring to the barrel bottom wall where the detonation begins (see Fig. 1). The initial components of velocity of media were imposed to be equal to zero.

The powder particles were assumed to be spherical, and their diameter varied from 10 to $160 \mu \mathrm{m}$. As mentioned before, a one-sided coupling was assumed regarding the interaction between the particle and surrounding gas (cf. also Ref 3-6). This means that only the gas affects the powder particle behavior. This assumption limits the applicability of presented model to qualitative analyses only. It should be noticed that in real spraying conditions, the powder fulfill coefficient can reach relatively high values; therefore, the volumetric ratio flow of the particles is also important to consider whether a flow is dilute (Ref 15). This state of the matter would impose necessity of application of fully Eulerian two-way coupling to describe the multiphase flow. The advantage of applied approach is that it significantly reduces computational cost (computing time) by enabling implementation of the discrete Lagrangian method to describe particle motion, which is equivalent to assumption of no effect of a solid phase flow on the gas flow. This approach significantly reduces number of equations describing model of the problem.

During the real GDS process of FeAl powder deposition, the following proportion was applied for a single cycle: $199 \mathrm{mg}$ of gas and $87 \mathrm{mg}$ of FeAl. Based on the experience of skilled attendants of the Perun-S gun, apparently only $20-50 \%$ of powder is effectively used during the whole process. This suggests the necessity for application of fully Eulerian approach to model the multiphase flow which in consequence leads to the above-mentioned difficulties. Oneway coupling results in overestimation of the critical particle diameter caused by both kinetic and thermal transport of energy from detonation flow to the condensed-aerosol phase. Thus, the performed analysis with application of discrete Lagrangian modeling of the particle motion, despite its limitations, resulted in more precise estimation of parameters of the real GDS process than the data available before (cf. Ref 1). Moreover, analysis of the obtained results enabled constructive "criticism" of our predecessors, where further steps, in numerical analysis of presented problem, will be concentrated on extension of numerical models. In Ref 16, a review of models of the interaction of spherical particles with gaseous media was presented.

Taking into account the obtained results, the following equation of particle motion was applied:

$\frac{\mathrm{d} \vec{v}_{\mathrm{p}}}{\mathrm{d} t}=F_{\mathrm{d}}\left(\vec{v}-\vec{v}_{\mathrm{p}}\right)$

where

$F_{\mathrm{d}}=\frac{18 \mu}{\rho_{\mathrm{p}} d_{\mathrm{p}}^{2}} \frac{C_{\mathrm{D}} R e}{24}$

in which

$\operatorname{Re}=\frac{d_{\mathrm{p}} \rho \cdot\left|v-v_{\mathrm{p}}\right|}{\mu}$

and the commonly used Morsi-Alexander formula (Ref $17,18)$ 
$C_{\mathrm{D}}=a_{1}+\frac{a_{2}}{R e}+\frac{a_{3}}{R e^{2}}$

was utilized for the drag coefficient $C_{\mathrm{D}}$ dependence on the Reynolds number $R e$. In the above expressions, $v_{\mathrm{p}}$ denotes the particle velocity, $d_{\mathrm{p}}$ is the diameter, $\rho_{\mathrm{p}}$ is the density of the particle material, and $a_{1}, a_{2}$ and $a_{3}$ are constants available in the literature sources (Ref 17, 18) and summarized in Table 2.

The next part, one of the most important elements of the whole analysis, is the estimation of the thermal history of powder particles. During acceleration, particles exchange heat with surrounding gas detonation products. In conditions of neglected phase transition, regarding low values of Biot number characterizing the investigated problem, the lumped parameters model for the particle heating process would have been successfully applied. Taking into account possible significant influence of phase transition phenomenon, authors decided to apply distributed parameters model for heating process. In order to assess the temperature distribution inside the particle, it is necessary to solve the Fourier-Kirchhoff equation (Ref 19), complemented with appropriate initial and boundary conditions, describing the heat transfer between the gases and particle surface. Assuming a spherical shape of the particles and homogenous distribution of heat flux on the surface of the particle, the equation of heat transport can be reduced to a onedimensional form:

$\frac{\partial T_{\mathrm{p}}}{\partial t}=\frac{1}{\rho_{\mathrm{p}} c\left(T_{\mathrm{p}}\right) r^{2}} \frac{\partial}{\partial r}\left(r^{2} \lambda_{\mathrm{p}} \frac{\partial T_{\mathrm{p}}}{\partial r}\right)$

In the above equation, $T_{\mathrm{p}}$ denotes the temperature of the particle material, $c\left(T_{\mathrm{p}}\right)$ its specific heat, and $\lambda_{\mathrm{p}}$ the thermal conductivity of the powder.

As the phase transition is concerned, instead of solving the classical Stephan problem, the melting enthalpy $\Delta h_{\text {melt }}$ was included into the particle specific heat dependence on the temperature. The melting was modeled with a rectangular "peak" of $\Delta T_{\text {phase }}=20 \mathrm{~K}$ width and a height of:

Table 2 Coefficients of Morsi-Alexander formula for different intervals of Reynolds number (Ref 17, 18)

\begin{tabular}{llll}
\hline$R e$ & \multicolumn{1}{c}{$a_{1}$} & \multicolumn{1}{c}{$a_{2}$} & \multicolumn{1}{c}{$a_{3}$} \\
\hline$R e<0.1$ & 0 & 24 & 0 \\
$0.1<R e<1$ & 3.69 & 22.73 & 0.0903 \\
$1<\operatorname{Re}<10$ & 1.222 & 29.1667 & -3.8889 \\
$10<\operatorname{Re}<100$ & 0.6167 & 46.5 & -116.67 \\
$100<\operatorname{Re}<1000$ & 0.3644 & 98.33 & -2778 \\
$1000<\operatorname{Re}<5000$ & 0.357 & 148.62 & $-4.75 \times 10^{4}$ \\
$5000<\operatorname{Re}<10,000$ & 0.46 & -490.546 & $57.87 \times 10^{4}$ \\
$10,000<\operatorname{Re}<50,000$ & 0.5191 & -1662.5 & $5.4167 \times 10^{4}$ \\
\hline
\end{tabular}

$\Delta c=\frac{\Delta h_{\text {melt }}}{\Delta T_{\text {phase }}}$

In order to include heat transfer between gas and particle surface, the Neumann boundary condition was applied:

$$
\begin{aligned}
\dot{q}_{\mathrm{r}=d_{\mathrm{p}} / 2} & =\left(\lambda_{\mathrm{p}} \frac{\partial T_{\mathrm{p}}}{\partial r}\right)_{r=d_{\mathrm{p}} / 2} \\
& =-\alpha_{\mathrm{t}}\left(T_{\mathrm{ps}}-T\right)-\varepsilon_{\mathrm{p}} \cdot \sigma\left[T_{\mathrm{ps}}^{4}-T_{\text {barrel }}^{4}\right]
\end{aligned}
$$

where $\alpha_{\mathrm{t}}$ is the heat transfer coefficient, $T_{\mathrm{ps}}$ the temperature of the particle surface, $\varepsilon_{\mathrm{p}}$ its surface emissivity, and $\sigma$ the Stefan-Boltzmann constant.

In the presented simplified model, like in models presented by our predecessors (Ref 3-6), it was assumed that even melted particles preserve their initial spherical shape. We did not account for particle evaporation or fragmentation. These assumptions were justified over the course of indirect experimental investigations-by comparing the powder feedstock particle size distribution with distribution of the powder that had been shot into the water. The comparison showed no significant differences. Surface tension forces seem to be strong enough to preserve molten alloy droplets from fragmentation. The same seems applicable for the evaporation effects. Taking into account the above-mentioned argument, $\alpha_{t}$ was estimated using the expression proposed by Ranz and Marshall (Ref 20), which is usually applied for interaction of gas with solid-state particles:

$N u_{\mathrm{p}}=\frac{\alpha_{\mathrm{t}} \cdot d_{\mathrm{p}}}{\lambda}=2+0.6 \operatorname{Re}^{0.5} \cdot \operatorname{Pr}^{0.33}$

where $N u_{\mathrm{p}}$ is the Nusselt number, and the Prandtl number $\mathrm{Pr}$ is as follows:

$\operatorname{Pr}=\frac{c_{\mathrm{p}} \cdot \mu}{\lambda}$

The assumed thermophysical properties of FeAl powder material are summarized in Table 3 (Ref 21).

Commenting on the values presented in Table 3, it should be precisely underlined that these values are

Table 3 Thermophysical properties of FeAl powder particles applied in simulations (Ref 21)

\begin{tabular}{llc}
\hline Parameter & \multicolumn{1}{c}{$\begin{array}{c}\text { Solid } \\
0-1395{ }^{\circ} \mathrm{C}\end{array}$} & $\begin{array}{c}\text { Liquid } \\
1395- \\
2690{ }^{\circ} \mathrm{C}\end{array}$ \\
\hline Density $\rho_{\mathrm{p}}, \mathrm{kg} / \mathrm{m}^{3}$ & 5800 & 4806 \\
Specific heat $c, \mathrm{~J} /(\mathrm{kg} \mathrm{K})$ & $0.301 \cdot t_{\mathrm{p}}+520$ & 890 \\
Thermal conductivity $\lambda_{\mathrm{p}}, \mathrm{W} /(\mathrm{m} \mathrm{K})$ & 15 & 71 \\
Surface emissivity $\varepsilon_{\mathrm{p}}$ & 0.7 & \\
Melting enthalpy $\Delta h_{\text {melt }}, \mathrm{kJ} / \mathrm{kg}$ & 288 & \\
\hline
\end{tabular}


estimates (Ref 16). Therefore, in order to avoid difficulties with reconfiguring the geometrical model of a spherical particle, the authors neglected the changes in the dimensions of the particles and hence in their density. The simplification effect on the particle dynamics can be estimated as follows.

As already stated, the phase transition causes a change in material density and in turn results in the increase in a particle diameter while the material melts. Thus, the relative change in the drag function from (13) is expressed as:

$\frac{F_{\mathrm{d} \text { melt }}}{F_{\mathrm{d} \mathrm{sol}}}=\frac{\frac{18 \mu}{\rho_{\mathrm{p} \text { melt }} d_{\mathrm{pmelt}}^{2}} \frac{C_{\mathrm{D} \text { melt }} R e_{\text {melt }}}{24}}{\frac{18 \mu}{\rho_{\mathrm{p} \mathrm{sol}} d_{\mathrm{psol}}^{2}} \frac{C_{\mathrm{D} \mathrm{sol}} R e_{\text {sol }}}{24}}$.

The ratio of the Reynolds number for two states of the particle can be estimated using of the following relations:

$\frac{R e_{\text {melt }}}{R e_{\text {sol }}}=\frac{d_{\text {p melt }}}{d_{\text {psol }}}$

and

$\frac{d_{\text {p melt }}}{d_{\text {p sol }}}=\sqrt[3]{\frac{\rho_{\text {p sol }}}{\rho_{\text {p melt }}}}$

After substitution into (19) and simplification, one can easily obtain:

$\frac{F_{\mathrm{d} \text { melt }}}{F_{\mathrm{d} \mathrm{sol}}}=\left(\frac{\rho_{\text {psol }}}{\rho_{\text {p melt }}}\right)^{2 / 3} \frac{C_{\text {D melt }}}{C_{\text {D sol }}}$.

where the first term can be estimated as:

$\left(\frac{\rho_{\text {p sol }}}{\rho_{\text {p melt }}}\right)^{2 / 3} \approx 1.13$.

The second term of Eq 22 converges monotonically to unity from below as the $C_{\mathrm{D}}$ converges monotonically to $a_{1}$ (cf. Eq 13c) from above as shown in Fig. 2. Sensitivity of the $C_{\mathrm{D}}$ to $\mathrm{Re}$ number changes increases while $R e$ tends to

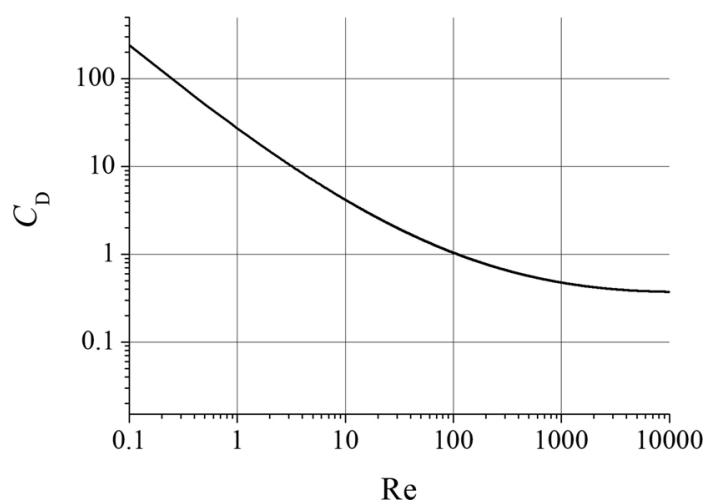

zero. As for most of the particle tracking time, we experience $R e>10$ and the analyzed relative difference (19) is not greater than 1.13. As the $R e$ number tends to zero, the difference decreases. In our case, minimum values of $R e$ number are achieved for the smallest particle of $10 \mu \mathrm{m}$ diameter, but the $R e$ number values lower than 2 were observed for less than $1 \%$ of the tracking time. For $R e=2$, the following estimation applies:

$\frac{C_{\text {D melt }}}{C_{\text {D sol }}} \approx 0.95$.

and the total relative difference (19) decreases to about 1.07 .

Influence of the diameter changes on the convective heat exchange of the particle surface can be estimated using the following ratio:

$\frac{d_{\mathrm{p} \text { melt }}^{2} \alpha_{\mathrm{tmelt}}}{d_{\mathrm{p} \mathrm{sol}}^{2} \alpha_{\mathrm{t} \mathrm{sol}}}=\frac{d_{\mathrm{pmelt}}}{d_{\mathrm{p} \mathrm{sol}}} \frac{2+0.6 R e_{\mathrm{melt}}^{0.5} \cdot \operatorname{Pr}^{0.33}}{2+0.6 \operatorname{Re}_{\mathrm{sol}}^{0.5} \cdot \operatorname{Pr}^{0.33}}$

The maximum value of the above-written relation can be estimated on 1.1.

The above calculated values characterize extreme contribution to the uncertainty budget at quantitative analyses. However, one should remember that the dynamic and thermal history of every tracked particle is so diversified that possible errors can be compensated due to changes in polarity of the velocity and temperature differences.

\section{Numerical Simulation Procedure}

Nowadays, many commercial computational codes are available to formulate and solve problems of fluid dynamics. In the presented case, Ansys Fluent CFD software was applied. Taking into account the dynamic character of the whole phenomenon with the presence of detonation and shock waves, it seems reasonable to apply an explicit scheme used in a density-based solver. Over the years, many so-called shock capturing numerical schemes have been developed. Most often, they are "upwind schemes," and one of the most well-known approaches to deal with the considered phenomena is the application of Roe's approximate Riemann solver, which was described in detail in (Ref 22, 23). This scheme is based on the Godunov method and has been modified to become effective despite its disadvantages and problems during investigations of extremely supersonic phenomena.

To briefly demonstrate the fundamentals of this approach, a simple system of partial differential equations is considered:

$\frac{\partial U}{\partial t}+\frac{\partial F}{\partial x}=S$

Fig. 2 Function $C_{\mathrm{D}}(R e)$ for the most sensitive region 
where $U$ denotes the vector of conserved variables, $F$ is the flux vector, and $S$ is the source vector.

In Roe's approach, the above equation has to be linearized to obtain the following form:

$\frac{\partial U}{\partial t}+\bar{A} \frac{\partial U}{\partial x}=S$

where estimation of the linearized Jacobian $\bar{A}=\frac{\partial F}{\partial U}$ is crucial and should satisfy certain conditions to ensure appropriate linearization. Conditions for matrix $\bar{A}$ were exactly defined in (Ref 22). For the investigated problem (25), in accordance with the Roe procedure, the following expression defining the numerical convective flux $F_{\mathrm{L}-\mathrm{R}}$ at the cells' interface can be written:

$F_{\mathrm{L}-\mathrm{R}}=\frac{1}{2}\left(F_{\mathrm{L}}+F_{\mathrm{R}}\right)-\frac{1}{2} \sum_{i=1}^{m} \bar{\alpha}_{i}\left|\bar{\lambda}_{i}\right| \bar{K}^{(i)}$

where $F_{\mathrm{L}}$ and $F_{\mathrm{R}}$ denote the value of flux at the left and right cells, and $\bar{\lambda}_{i}$ denotes the eigenvalues of the linearized Jacobian matrix $\bar{A}$. The "wave strength" $\bar{\alpha}_{i}$ is evaluated based on the expression:

$\Delta U_{\mathrm{L}-\mathrm{R}}=U_{\mathrm{R}}-U_{\mathrm{L}}=\sum_{i=1}^{m} \bar{\alpha}_{i} \bar{K}^{(i)}$

where $\bar{K}^{(i)}$ is the right eigenvector for the linearized Jacobian matrix.

To obtain a spatially second-order scheme, the flux (26) is slightly modified (Ref 22).

In order to ensure satisfactory accuracy, the well-known and commonly used fourth-order Runge-Kutta scheme was applied for timestepping (Ref 23).

During the detonation process, a fixed timestep was applied. Its value satisfied the condition of equality of the CFL number to 0.66 , where the CFL was calculated using the detonation velocity and the smallest value of cell dimension. During the outflow of gases from the barrel, higher values of the CFL number were applied (continuously increased up to 0.8 ).

Simulations were conducted on the mesh presented in Fig. 3. The barrel region and the region near the barrel, due to predicted high values of gradients of parameters, were finely meshed. In this region, the cell size was equal to $1 \mathrm{~mm}$. For the more distant "environmental" region, the mesh size was increased up to $3 \mathrm{~mm}$.

For numerical simulations of the heat transfer process inside the particle, the classical second-order finite difference scheme for Eq 14 has been applied (Ref 24). In this case, the same timestep was imposed and the spatial step was equal to $1 \%$ of the particle's radius.

\section{Results and Discussion}

The formulation of the analytical and numerical model description for the heat, mass and momentum transfer phenomenon to the $\mathrm{FeAl}$ particle thermal state evaluation was based on the GDS experiment carried out in the Ukrainian Academy of Sciences, at E.O. Paton Electric Welding Institute, Kiev with "Perun-S" detonation system (Ref 1).

The feedstock powder material consists of Fe40A10.05Zr at. $\%+50 \mathrm{ppm} \mathrm{B} \mathrm{particles} \mathrm{with} \mathrm{wide} \mathrm{size}$ granulation distribution ranging from 10 to $160 \mu \mathrm{m}$, obtained by vacuum inert gas atomization (VIGA) in CEA, Grenoble, but volumetric particle size distribution of the feedstock powder applied in the GDS experiments was dominated by particles of equivalent diameter ranging from about 38 to $75 \mu \mathrm{m}$-after sieving (Ref 1). It was determined that the best metallurgical quality of the coatings is achieved by employing powder particles the sizes of which are 40-63 $\mu \mathrm{m}$ (Ref 25) and (38-75) $\mu \mathrm{m}$ (Ref 26), respectively.

The GDS process was carried out on C45 plain carbon steel with the following parameters: volume fractions of reactants as 0.202 propane and 0.685 oxygen; detonation frequency and spraying distance, respectively, $6.66 \mathrm{~Hz}$ and $70 \mathrm{~mm}$; powder injection point of $275 \mathrm{~mm}$ from the barrel bottom.

Having carried out GDS process in 100 shooting cycles, repeatable qualities of the $\mathrm{FeAl}$ coating were achieved in the shape of single spot at constant distance between gun barrel and the surface of substrate material (with no mutual movement in a plane perpendicular to the axis of the stream of detonation products).
Fig. 3 Numerical mesh applied during calculations $(1-$ barrel region; 2 -coated surface; 3 environment region)

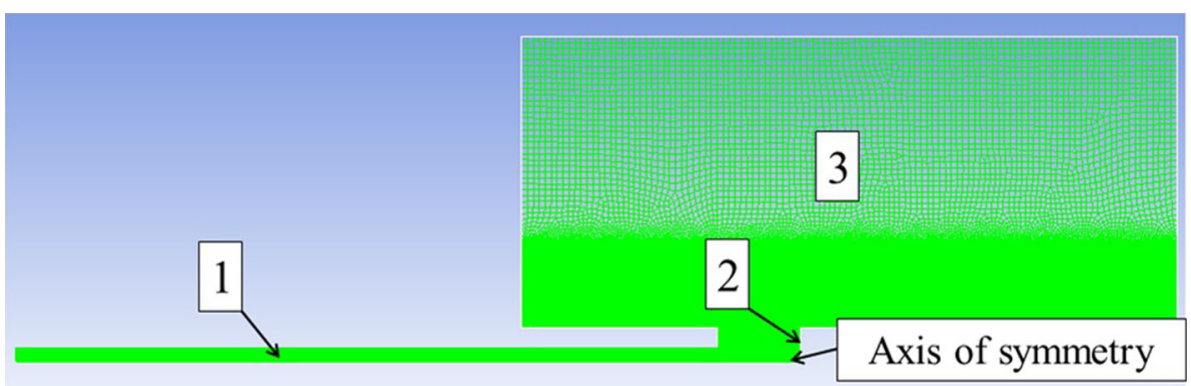


The deposited particles of the FeAl powder influenced by high kinetic energy, temperature and the rate of deformation due to the hydrodynamic impact of the detonation products undergo plastic deformation and geometrical changes turning into the $\mathrm{FeAl}$ coating, the porosity of which is less than $0.5 \%(\operatorname{Ref} 1)$.

As a result of the conducted simulations, the spatial distributions of the gas physical parameters, as well as the time history of the particles' state and motion, were obtained. In Fig. 4, the spatial distributions of physical parameters along the barrel axis during the detonation process are shown.

In Fig. 5, the particle velocities as a function of time are presented. The obtained results comply with the results of calculations presented in (Ref 6) regarding maximum particle velocities. An increase in the particle diameter seriously delays the impact, which extends the time of thermal interaction between gases and particles.

Maximum values of powder particles' muzzle velocity obtained in an experimental way with the application of the Perun-S gun were in the range of 650 to $850 \mathrm{~m} / \mathrm{s}$ (Ref 27). Comparison of the theoretical effects with experiments suggests an acceptable discrepancy of the results: Particles
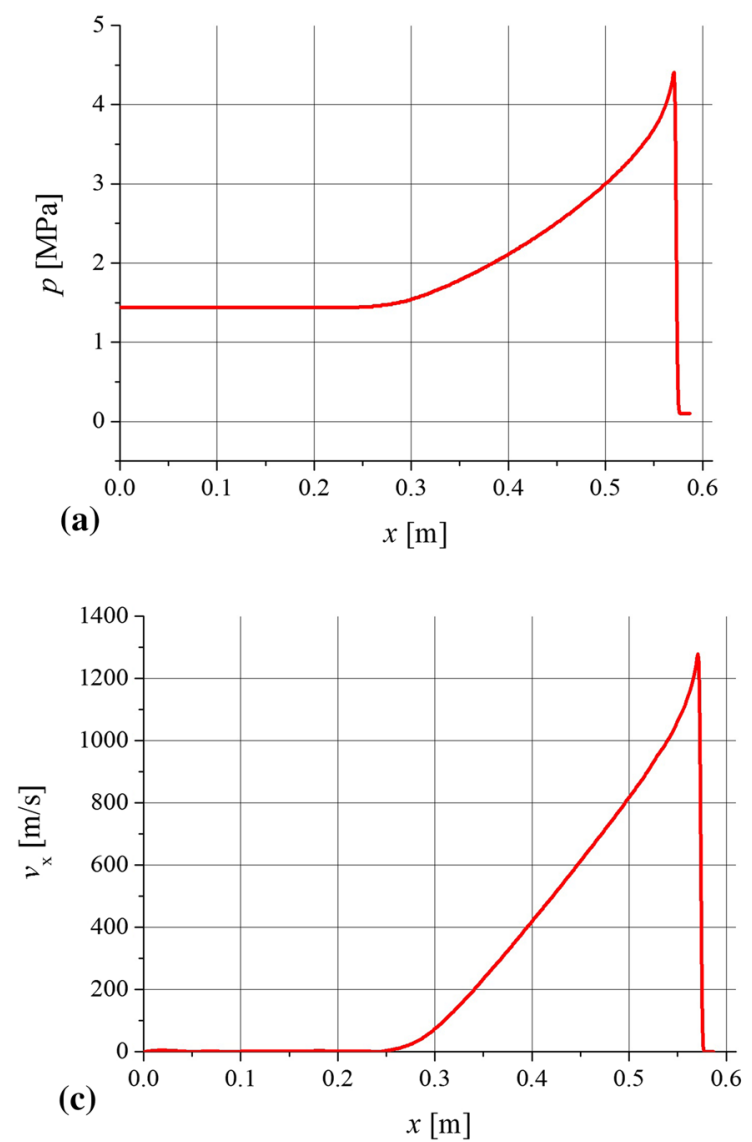

characterized by diameters of 10 and $20 \mu \mathrm{m}$ leave the barrel with velocity values equal to 920 and $710 \mathrm{~m} / \mathrm{s}$, respectively.

The gaseous-phase parameters such as gas velocity, density and temperature experienced by particles in the GDS process are shown in Fig. 6, 7 and 8. First peaks that can be observed are connected with a phenomenon of detonation wave passing by all particles at the same time, as we assumed that injection point is the same for all

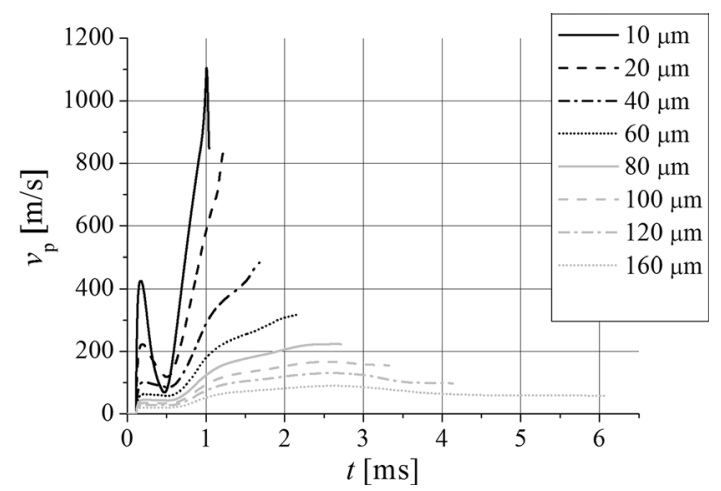

Fig. 5 Course of powder particles' velocities as a function of time

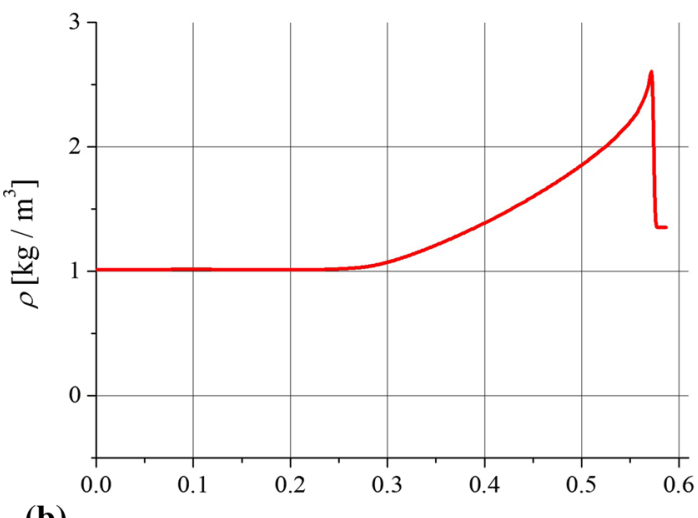

(b)

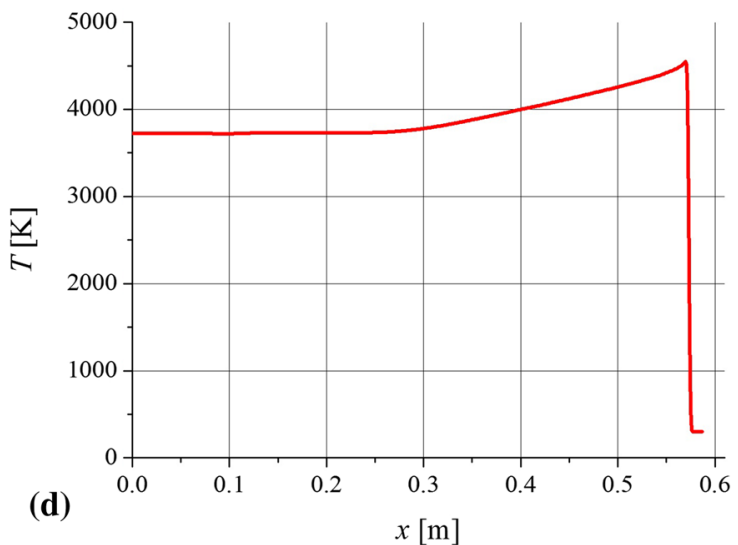

Fig. 4 Spatial distribution of physical parameters of gas as a function of barrel length during the detonation process (a pressure; b density; c axial component of velocity; $d$ temperature) 


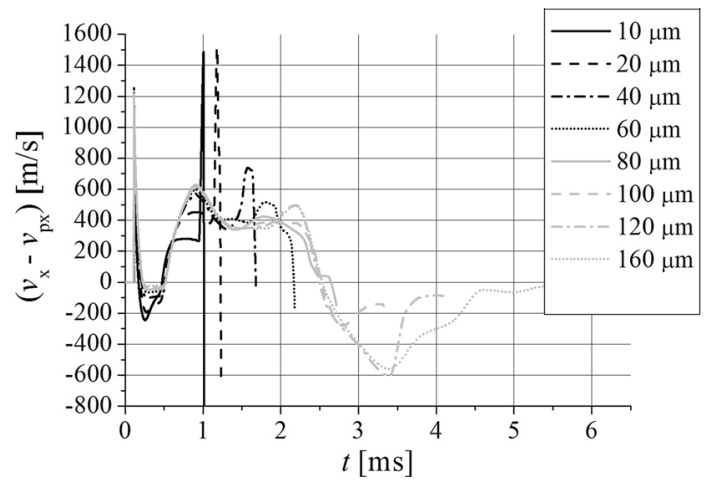

Fig. 6 Courses of gas relative velocities as a function of time

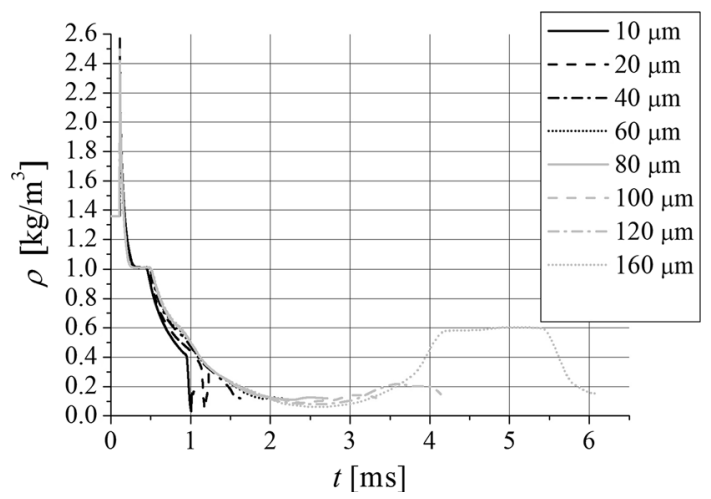

Fig. 7 Courses of gas density, in the vicinity of the particle surface, as a function of time

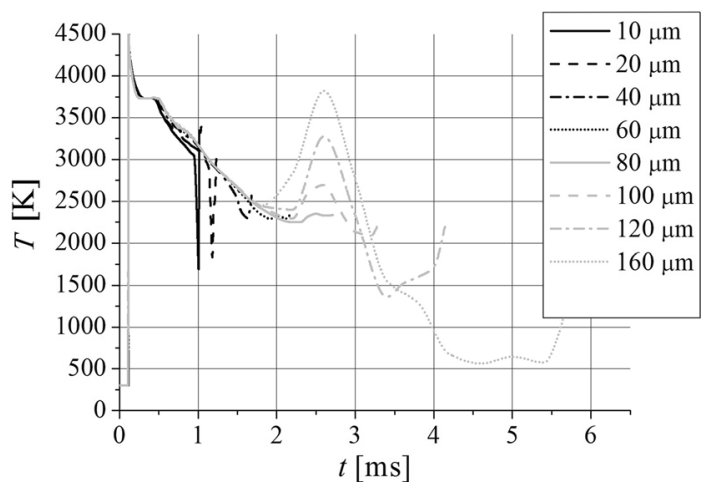

Fig. 8 Courses of gas temperature, in the vicinity of the particle surface, as a function of time

particles. The following deceleration (Fig. 5) is caused by the flow stagnation that lasts up to the moment at which the wave front reaches the barrel end. From that moment, the outflow of compressed gases accelerates particles still remaining inside. The smallest particles decelerate once again while reaching the outside decompression zone (Fig. 5, $10 \mu \mathrm{m}$ curve). The deceleration of the biggest particles is caused both by deceleration of the internal flow due to the internal pressure relaxation and due to the outside flow decompression. All the discussed instantaneous

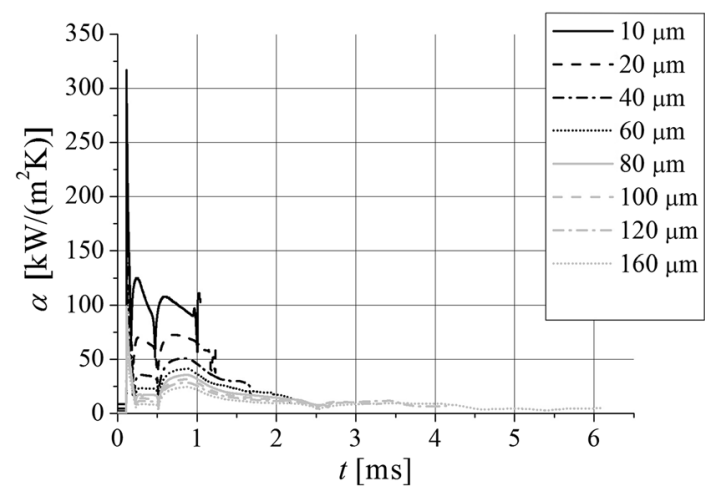

Fig. 9 Courses of heat transfer coefficient as a function of time

flow phenomena shape the heat transfer condition, and the changes observed in other figures are their effects.

Regarding the calculated values of the analyzed parameters, it is reasonable to present the gas-particle heat transfer characteristics. In Fig. 9, the heat transfer coefficient evolution in time (cf. Eq 16) is shown. The depicted characteristics reflect changes of the accelerated particle velocity in relation to the velocity of the surrounding combustion gases. As expected, the obtained heat transfer coefficient values are extremely high for small particles (Ref 19), and these particles are exposed to a high-temperature flow at the most. This situation generates a possible opportunity for melting the external part of the powder particle. In order to demonstrate the effect of heating during the whole process, the changes of the particles' surface temperature as a function of time and the radial temperature distribution for the investigated objects are presented in Fig. 10 and 11.

The above presented results show a strong dependence of particle motion and heat transfer parameters on particle dimension. These parameters are the particle residence time, particle terminal velocity and particle terminal temperature. The residence time defines a period of exposure of the particle material to highly reactive combustion gases. With increasing particle diameter, the time for oxide formation increases too. From the terminal ballistics, it is known that the velocity of powder particle strongly affects its deformation during the impact into the coated surface (Ref 28). Additionally, the material temperature, obviously, affects the mechanical properties of particles as a result of phase transitions and chemical reactions. The results suggest that the particles which are most deformed during the impact are the smallest ones.

Analysis of the obtained results indicates that there is a critical diameter of particle below which the material melts in the whole volume. In our case, the particle critical diameter was evaluated to be equal to approximate $80 \mu \mathrm{m}$. Moreover, what seems to be interesting is that the radial distribution of temperature is relatively homogenous for 


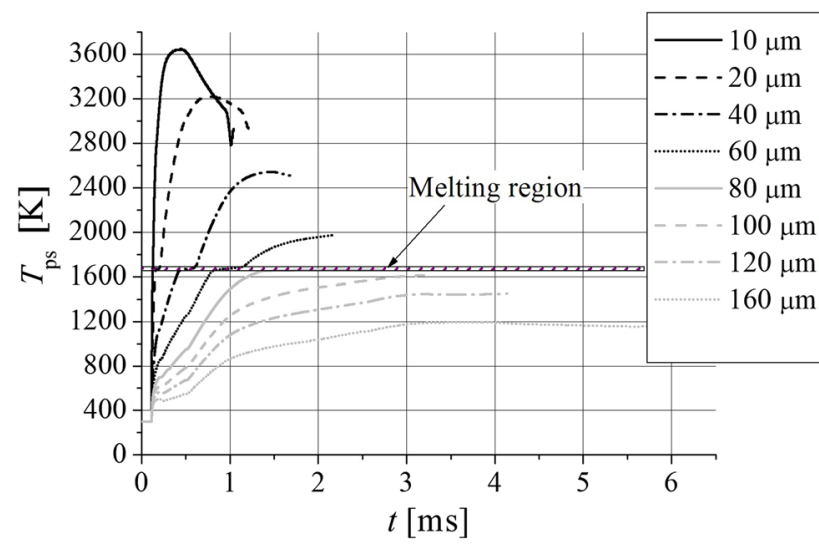

Fig. 10 Courses of particle surface temperature as a function of time

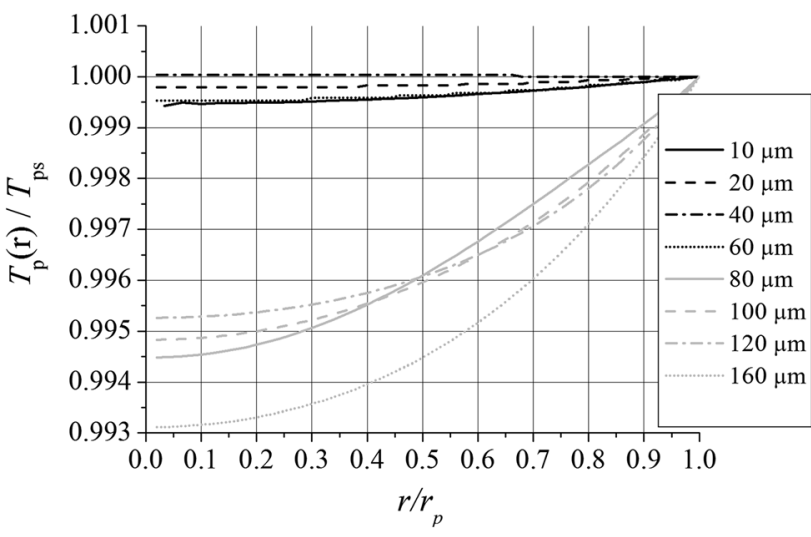

Fig. 11 Normalized radial distribution of terminal-at impacttemperature inside the particle

each considered diameter of particle, which is the result of the short characteristic time of the heating process in comparison with the time of motion. This effect is especially noticeable for melted particles, due to high thermal conductivity of melted material. The obtained results indirectly prove that the thermal lag due to the internal heat conduction can be neglected in case of under-consideration powder material.

Unfortunately, experimental verification of the obtained values of temperature is possible only by making use of indirect methods based on investigations of the splat structure. However, the conducted analyses make it possible to identify crucial phenomena, such as melting, chemical reactions and particle softening, shaping the specific properties of the coating.

The results of structure examination of the $\mathrm{Fe}-\mathrm{Al}$-type coating sprayed in the GDS process on a C45 steel substrate were presented in paper (Ref 29), in which the structure was analyzed with SEM/EDS, TEM/SAE and XRD methods. The results allowed explaining the formation mechanism of the coating morphology with a contribution of intermetallic phases such us $\mathrm{Fe}_{3} \mathrm{Al}, \mathrm{FeAl}$, $\mathrm{FeAl}_{2}$ and $\mathrm{Fe}_{2} \mathrm{Al}_{5}$. It was established that the GDS coating displayed sublayer morphology of alternate flattened and partially melted grains with wide range of $\mathrm{Al}$ content between 39 and 63 at.\% (Ref 29). Partial melting of the individual powder particles resulted in the in situ formation of the amorphous grains and, subsequently, columnar crystals of the Fe-Al-type phases, sequentially formed in the volume of lamellar splats of the coating. It was found that the inherent mechanism of the $\mathrm{Fe}-\mathrm{Al}$ coating formation is attributed to plastic deformation and geometrical changes of the strongly heated powder particles, which undergo plastic deformation and geometrical changes in the GDS process conditions (discussed above).

The geometrical changes and simultaneous indications of melting of the $\mathrm{Fe}-\mathrm{Al}$ coating material (in microareas) confirm high velocity of the FeAl powder particles, additionally subjected to partial melting at a very high temperature of gas detonation products.

In general, while characterizing a specific analyzed GDS process, the obtained data are broadly consistent with the results of the most similar studies presented in (Ref 3-6).

The velocity range of $\mathrm{Al}_{2} \mathrm{O}_{3}$ powder particle with a diameter of $20 \mu \mathrm{m}$, as presented in (Ref 3 ), is similar to our results for FeAl particles, following the application of onedimensional detonation model for a dissimilar explosive gas mixture consisting of hydrogen and oxygen or acetylene and oxygen (Ref 3 ). However, the differences occurring in the values of particle velocity undeniably result from the application of different explosive mixtures and powder materials of various density $\left(3.95 \mathrm{~g} / \mathrm{cm}^{3}\right.$ for $\mathrm{Al}_{2} \mathrm{O}_{3}$ and $5.56 \mathrm{~g} / \mathrm{cm}^{3}$ for $\mathrm{FeAl}$, respectively) (Ref 1, 3). Further numerical investigation on the flow of a two-phase gas-particle stream under the detonation conditions with propane involvement has enabled the determination of thermal interaction between the WC powder particles and the gaseous medium, taking into account the influence of PIP on a single particle (Ref 4). Contrary to our results concerning the FeAl powder, E. Kadyrov did not obtain melting of the powder material at a relatively low temperature of WC particles (approximately $2000 \mathrm{~K}$ ), despite using a much longer barrel of $1.8 \mathrm{~m}$ in length (Ref 4). The results obtained and presented by E. Kadyrov (Ref 4) confirm our hypothesis, which states that in dependence on the coating material and the conditions of the GDS process using a propane-oxygen explosive gas mixture, there exists an upper threshold of powder particles that are not subjected to melting. Furthermore, impressive properties of sprayed coatings with low porosity, which maintain their chemical and phase composition, are the result of a strong plastic deformation, which highly heated powder particles in the solid state are subjected to when colliding with the steel substrate material due to very high kinetic energy. It is 
worth emphasizing that based on the analysis of gas flow evolution and shock wave decay in detonation thermal spraying systems, Ramadan and Barry Butler (Ref 4, 5) showed that the two-phase gaseous-powder stream with particles of $\mathrm{Al}_{2} \mathrm{O}_{3}$ transported under specific detonation conditions with an equivalent diameter of $20 \mu \mathrm{m}$ is capable of melting at a temperature of roughly $2300 \mathrm{~K}$ at a velocity comparable to the results obtained in our research for $\mathrm{FeAl}$ particles. Numerical analysis (Ref 4) was based on solving the mathematical model of the Euler equations for chemical reactions with variable gas properties for axisymmetric 2D flow. In their analysis, Ramadan and P. Barry Butler (Ref 4,5 ), similar to our research, developed a lumpedparameter model with one-sided coupling in order to describe the propulsion of powder particles. Having obtained comparable heat transfer coefficients with the results of Ramadan and Barry Butler (Ref 4, 5), we also took into account the heat transport inside particles, which enhances the applicability of the model developed, likewise in the case of materials exhibiting very low thermal conductivity.

The obtained methodology of numerical modeling was proved to be effective in qualitative analyses. As far as quantitative aspects are concerned, it is very difficult to assess the accuracy of the performed simulation because of difficulties in the experimental determination of the analyzed particle dynamics and thermal state.

Nevertheless, even in the present state, the simulation provided valuable results that can help to explain the mechanisms of formation of the analyzed GDS coating. In contrast to most of the other spraying techniques, under GDS conditions, transient mass and heat flow phenomena play a major role. A relatively short exposition time of the analyzed particle to a shock detonation wave creates conditions that strongly diversify particles depending on their diameter and initial position. The resulting coating is created from particles whose states are much more differentiated than are usual. This is the reason for the lower densities of GDS coatings (cf. Ref 30). On the other hand, complicated coupled heat and mass transfer phenomena accompanying the GDS make theoretical prediction of spraying effects difficult. This explains why not all hopes placed in the GDS technology have come true (cf., e.g., Ref 31 ). However, the developed methodology can help in the optimization of the GDS process parameters even by creating the possibility of sensitivity analysis.

\section{Conclusions}

The main purpose of this research was to adopt numerical simulation procedures and to develop an effective methodology to perform analyses focused on a certain detonation gun spraying example. The analyzed case was $\mathrm{Fe} 40 \mathrm{Al}$ at.\% powder deposition onto a $\mathrm{C} 45$ steel substrate (Ref 29, 32). While developing the numerical model, a hybrid approach was applied: The combustion gases' parameters were calculated by applying thermochemical code, and then, the detonation gas flow was analyzed in a 2-D axisymmetric geometry using commercial CFD software. The material property data reflected the thermophysical data of FeAl powder (Ref 1).

According to the detailed results, the following conclusions can be drawn from the study conducted:

- The obtained results are in qualitative agreement with the literature data (Ref 5, 6), which proves the effectiveness of the applied modeling methodology, that is, the hybrid approach with the application of commercial CFD software.

- There is a critical diameter of particle below which the material melts in the whole volume. In accordance with numerical data, this value can be estimated on $80 \mu \mathrm{m}$. On the other hand, the experimental approach provides value of $60 \mu \mathrm{m}(\operatorname{Ref} 29,32)$. Possibly applied one-way coupling results in overestimation of the critical particle diameter because of both kinetic and thermal transport of energy from detonation flow to the condensedaerosol phase.

- Due to the relatively low surface heat transfer conductance in comparison with thermal conduction inside the particle, the particle temperature is almost uniform and there is no indication of partial particle melting.

- Quantitative verification of the obtained results is extremely difficult due to the impossibility of application of direct methods.

- The obtained data provide an explanation for the resulting GDS coating morphology (Ref 29, 32).

- In spite of the amendments introduced to the modeling methodology in relation to (Ref 3,4), the proposed model cannot still be treated as quantitative one and its applicability is limited to just more accurate qualitative analyses. Analyzing still remaining deficiencies, the most problematic is assumption of a one-way coupling between the gaseous and aerosol phases. However, accounting for the momentum and thermal energy transfer from the condensed phase to combustion gases should result in decreasing particle terminal velocity and temperature as the detonation energy should distribute between the two phases. This in turn should result in a better compliance between the modeling results and the experimentally established data on unmelted inclusions within the analyzed FeAl GDS coating.

In general, the proposed numerical modeling methodology proved to be effective and will be applied in analyses of 
GDS experiments performed with different spraying parameters.

Acknowledgments The authors wish to thank PhD Dariusz Zasada from the Military University of Technology, Poland for his support in the SEM experimental work. The authors express their thanks to Prof. Yurij Borisov from the E.O. Paton Electric Welding Institute, National Academy of Science of Ukraine, for GDS experiment. Financial support from Polish National Science Centre, Poland, Research Project No. 2015/19/B/ST8/02000, is gratefully acknowledged.

Open Access This article is distributed under the terms of the Creative Commons Attribution 4.0 International License (http://crea tivecommons.org/licenses/by/4.0/), which permits unrestricted use, distribution, and reproduction in any medium, provided you give appropriate credit to the original author(s) and the source, provide a link to the Creative Commons license, and indicate if changes were made.

\section{References}

1. C. Senderowski, Żelazowo-aluminiowe intermetaliczne systemy powtokowe uzyskiwane $z$ naddźwiękowego strumienia metalizacyjnego (Iron-Aluminium Intermetallic Coatings Synthesized By Supersonic Metallization Stream) (Bel Studio, Warsaw, 2015), ISBN 978-83-7798-227-3 (in Polish)

2. P.L. Fauchais, V.R. Heberlain, and M.I. Boulos, Thermal Spray Fundamentals. From Powder to Part, Springer, New York, 2014

3. E. Kadyrov and V. Kadyrov, Gas Dynamical Parameters of Detonation Powder Spraying, J. Therm. Spray Technol., 1995, 4(3), p 280-286

4. E. Kadyrov, Gas-Particle Interaction in Detonation Spraying Systems, J. Therm. Spray Technol., 1996, 5(2), p 185-195

5. K. Ramadan and P.B. Butler, Analysis of Gas Flow Evolution and Shock Wave Decay in Detonation Thermal Spraying Systems, $J$. Therm. Spray Technol., 2004, 13(2), p 239-247

6. K. Ramadan and P.B. Butler, Analysis of Particle Dynamics and Heat Transfer in Detonation Thermal Spraying Systems, J. Therm. Spray Technol., 2004, 13(2), p 248-264

7. A. Sova, D. Pervushin, and I. Smurov, Development of Multimaterial Coatings by Cold Spray and Gas Detonation Spraying, Surf. Coat. Technol., 2010, 205, p 1108-1114

8. I.S. Batraev, V.Y. Ulianitsky, and D.V. Dudina, Detonation Spraying of Copper: Theoretical Analysis and Experimental Studies, Mater. Today Proc., 2017, 4(11), p 11346-11350

9. V.Y. Ulianitsky, D.V. Dudina, I.S. Batraev, A.I. Kovalenko, N.V. Bulina, and B.B. Bokhonov, Detonation Spraying of Titanium and Formation of Coatings with Spraying Atmosphere-Dependent Phase Composition, Surf. Coat. Technol., 2015, 261, p 174-180

10. K.V. Korytchenko, S. Essmann, D. Markus, U. Maas, and E.V. Poklonskii, Numerical and Experimental Investigation of the Channel Expansion of a Low-Energy Spark in the Air (Comb. Scien. and Tech., 2018), pp. 1-26, ISSN: 0010-2202. https://doi. org/10.1080/00102202.2018.1548441

11. Ansys Fluent 12.0. Theory Guide (Ansys Inc., 2009)

12. E. Włodaraczyk, Podstawy fizyki wybuchu (Fundamentals of Physics of Explosion) (Military University of Technology, Warsaw, 2012), ISBN 978-83-89399-99-1 (in Polish)

13. E. Orlenko et al., Fizika vzryva (Physics of Explosion) (Nauka, Moscow, 2004), ISBN 5-9221-0218-4 (in Russian)

14. S. Gordon, Thermodynamic and Transport Combustion Properties of Hydrocarbons with Air, I-Properties in SI Units. NASATechnical Paper 1906 pt. 1, July 1982
15. S. Martin and J.R. Williams, Multiphase Flow Research, Nova Science Publishers, Hauppauge, 2009

16. A. Panas and T. Fafiński, Analiza porównawcza wybranych modeli ruchu cząstki sferycznej w jednowymiarowym przepływie dwufazowym (Comparative Analysis of Response of a Spherical Particle to One Dimensional Two-Phase Fluid Flow), Eng. Model., 2008, 5(36), p 387-394 (in Polish)

17. S.A. Morsi and A.J. Alexander, An Investigation of Particle Trajectories in Two-Phase Flow Systems, J. Fluid Mech., 1972, 55, p 193-208

18. Y. Sun, Z. Guan, H. Gurgenci, X. Li, and K. Hooman, A Study on Multi-nozzle Arrangement for Spray Cooling System in Natural Draft Dry Cooling Tower, Appl. Therm. Eng., 2017, 124, p 795814

19. F.P. Incropera, D.P. de Witt, T.L. Bergmann, and A.S. Lavine, Fundamentals of Heat and Mass Transfer (Wiley, Hoboken, 2007), ISBN 978-0-471-45728-2

20. W. Ranz and W. Marshall, Evaporation from Drops, Chem. Eng. Prog., 1952, 48, p 141-146

21. C. Senderowski, A.J. Panas, J. Paszula, and Z. Bojar, Ocena stopnia ogrzania cząstek proszku $\mathrm{FeAl} w$ procesie natryskiwania gazodetonacyjnego (GDS) (The Evaluation of FeAl Particle Thermal Response in Gas Detonation Thermal Spraying Process), Mater. Eng., 2013, 6, p 849-853 (in Polish)

22. E.T. Toro, Riemann Solvers and Numerical Methods for Fluid Dynamics (Springer, Berlin, 2009), ISBN 978-3-540-49834-6

23. P. Wesseling, Principles of Computational Fluid Dynamics (Springer, Berlin, 2001), ISBN 978-3-642-05146-3

24. A.A. Samarskij, Teorija Raznostnyh Shem (Theory of Differential Schemes), Nauka, Moscow, 1977 (in Russian)

25. C. Senderowski and Z. Bojar, Gas Detonation Spray Forming of Fe-Al Coatings in the Presence of Interlayer, Surf. Coat. Technol., 2008, 202, p 435-447

26. C. Senderowski and Z. Bojar, Influence of Detonation Gun Spraying Conditions on the Quality of Fe-Al Intermetallic Protective Coatings in the Presence of $\mathrm{NiAl}$ and $\mathrm{NiCr}$ Interlayers, $J$. Therm. Spray Technol., 2009, 18(3), p 185-195

27. C. Senderowski, Unpublished Results of Experimental Researches, Military University of Technology, Warsaw, 2015 (in Polish)

28. W.Y. Li, K. Yang, S. Yin, and X.P. Guo, Numerical Analysis of Cold Spray Particles Impacting Behavior by the Eulerian Method: a Review, J. Therm. Spray Technol., 2016, 25(8), p 1441-1460

29. C. Senderowski, A.J. Panas, B. Fikus, and W. Wołczyński, Mechanisms of Structure Formation and Thermo-Physical Properties of Gas Detonation Sprayed Fe-Al Type Coatings, in Proceedings of International Thermal Spray Conference Exposition, ed. by F. Azarmi et al. 7-10 May 2018, Orlando FL, USA (ASM International, Materials Park OH, 2018), eISBN: 978-1-62708160-3, pp. 521-527

30. F.N. Longo, Coating Processing in Handbook of Thermal Spray Technology, J.R. Davis, Ed., ASM International, Materials Park, 2004, p 120-127 ISBN 0-87170-795-0

31. Y.A. Kharlamov, Materials Engineering Forum. Detonation Spraying of Protective Coatings, Mater. Sci. Eng., 1987, 93, p 137

32. A.J. Panas, C. Senderowski, B. Fikus, W. Wołczyński, Thermal Stability of Thermophysical Properties of Multiphase Fe-Al Intermetallic/Oxide Ceramics Coatings Deposited by Gas Detonation Spraying, in Proceedings of International Thermal Spray Conference Exposition, F. Azarmi et al. 7-10 May 2018, Orlando FL, USA (ASM International, Materials Park OH, 2018), eISBN: 978-1-62708-160-3, pp. 307-312 